\title{
Occurrence of brassinosteroids and influence of 24-epibrassinolide with brassinazole on their content in the leaves and roots of Hordeum vulgare L. cv. Golden Promise
}

\author{
Andrzej Bajguz $^{1} \mathbb{D} \cdot$ Wacław Orczyk $^{2} \cdot$ Agnieszka Gołębiewska $^{1} \cdot$ Magdalena Chmur $^{1}$ - Alicja Piotrowska-Niczyporuk ${ }^{1}$
}

Received: 13 October 2018 / Accepted: 21 December 2018 / Published online: 29 December 2018

(c) The Author(s) 2019

\begin{abstract}
Main conclusion 24-epibrassinolide overcame the inhibitory effect of brassinazole on the barley growth and the content of brassinosteroids.
\end{abstract}

The present work demonstrates the occurrence of mainly castasterone, brassinolide and cathasterone and lower amounts of 24-epibrassinolide, 24-epicastasterone, 28-homobrassinolide, typhasterol, 6-deoxocastasterone and 6-deoxotyphasterol in 14-day-old de-etiolated barley (Hordeum vulgare L. cv. Golden Promise). We also investigated the endogenous level of brassinosteroids (BRs) in barley seedlings treated with 24-epibrassinolide (EBL) and/or brassinazole (Brz). To our knowledge, this is the first report related to the occurrence of BRs and application of EBL and Brz in terms of the endogenous content of BRs in barley. Brz as a specific inhibitor of BR biosynthetic reactions decreased the level of BRs in the leaves. Application of EBL showed a weak promotive effect on the BR content in Brz-treated seedlings. Brz also inhibited growth of the seedlings; however, addition of EBL overcame the inhibition. The EBL applied alone at $0.01-1 \mu \mathrm{M}$ increased the BR level in the leaves but at $10 \mu \mathrm{M}$ lowered the BR content. In opposition to leaves, the Brz in the concentration range from 0.1 to $1 \mu \mathrm{M}$ did not significantly affect the content of BRs in the roots. However, application of $10 \mu \mathrm{M}$ Brz caused BRs to decrease, but treatment of EBL concentrations overcame the inhibitory effect of Brz.

Keywords Barley · Distribution · Inhibition · Interaction · Promotive effect

\section{Introduction}

Brassinosteroids (BRs), a class of phytohormones, are essential for plant growth and development, including the promotion of stem elongation, pollen tube growth, leaf bending, leaf unrolling, root inhibition and cell division (Kutschera and Wang 2012; Bajguz and Piotrowska-Niczyporuk 2014; Tarkowska and Strnad 2018). More than 60 compounds with structures related to that of brassinolide (BL) have been

Andrzej Bajguz

abajguz@uwb.edu.pl

1 Department of Plant Biochemistry and Toxicology, University of Bialystok, Faculty of Biology and Chemistry, Institute of Biology, 1J Konstantego Ciolkowskiego St., 15-245 Białystok, Poland

2 Department of Genetic Engineering, Plant Breeding and Acclimatization Institute, National Research Institute, Radzikow, 05-870 Blonie, Poland isolated from different plant organs such as pollen, anthers, seeds, leaves, stems, roots, flowers and grain as well as insect and crown galls. The presence of some bioactive BRs, i.e. $\mathrm{BL}$, castasterone (CS), 6-deoxocastasterone (6dCS), teasterone (TE) and typhasterol (TY) was confirmed in many plant species that belong to all phyla of the plant kingdom like algae, pteridophytes, gymnosperms, monocots and dicots (Zhabinskii et al. 2015; Kanwar et al. 2017; Zullo 2018).

BRs are synthesised from phytosterols (campesterol and campestanol, $\mathrm{CN}$ ) through complex oxidative reactions resulting in the synthesis of BL via two parallel pathways, named the early and the late C-6 oxidation pathways. CN is, respectively, converted to 6-oxocampestanol (6-oxoCN), cathasterone (CT), TE, 3-dehydroteasterone (3DT), TY and then to CS, in the early C-6 oxidation pathway. In the second parallel pathway, $\mathrm{CN}$ is hydroxylated at $\mathrm{C}-22$ to form 6-deoxocathasterone (6dCT) and then is converted to 6-deoxy forms of TE, 3DT, TY and CS. These pathways converge at CS, which ultimately leads to the synthesis of 
BL (Ye et al. 2011; Zhao and Li 2012; Chung and Choe 2013).

Brassinazole (Brz) is a triazole derivative and an inhibitor of BR biosynthesis that has been developed to probe the functions of BRs. It can induce morphological changes, including dwarfism and altered leaf colour and curling, in dark-grown Arabidopsis thaliana and light-grown cress (Lepidium sativum) that are rescued by co-application of BR. Brz blocks the conversion of $\mathrm{CN}$ to $6 \mathrm{dCT}, 6 \mathrm{dCT}$ to 6-deoxoteasterone (6dTE), 6-oxoCN to CT and CT to TE in the biosynthetic pathways of BRs (Asami and Yoshida 1999; Asami et al. 2000, 2003).

In this study, we report the detection of several intermediates of BR pathways in the seedlings of Hordeum vulgare cv. Golden Promise. The ability of Brz to inhibit the biosynthesis of BRs was evaluated in barley leaves and roots. The application of exogenous BR against the inhibitory effect of Brz on the content of BRs is still poorly studied. Therefore, the aim of this paper was to use the combination of 24-epibrassinolide (EBL) and Brz to investigate the level of endogenous BRs.

\section{Materials and methods}

\section{Plant material and growth condition}

Kernels of Hordeum vulgare cv. Golden Promise were surface sterilised by immersion, first treated with $70 \%$ ethanol (EtOH) (5 min), then $4 \%$ sodium hypochlorite $(10 \mathrm{~min})$ and thoroughly rinsed with distilled water (3 times, $10 \mathrm{~min}$ ). Kernels were sown in Petri dishes (diameter $10 \mathrm{~cm}, 10$ kernels per dish) on moistened filter paper and kept in the dark for $24 \mathrm{~h}$ in $6{ }^{\circ} \mathrm{C}$, then for 3 days in $22^{\circ} \mathrm{C}$. Then, germinated kernels (10 seedlings per pot) were transferred to plastic vessels (diameter $10 \mathrm{~cm}$, height $5 \mathrm{~cm}$ ) containing $250 \mathrm{~mL}$ of Hoagland solution and the appropriate amount of EBL and/ or Brz. The following compounds of Hoagland solution were used: $6.5 \mathrm{mM} \mathrm{KNO}_{3}, 4.0 \mathrm{mM}$ solution of $\mathrm{Ca}\left(\mathrm{NO}_{3}\right)_{2}, 2.0 \mathrm{mM}$ $\mathrm{NH}_{4} \mathrm{H}_{2} \mathrm{PO}_{4}, 2.0 \mathrm{mM}$ solution of $\mathrm{MgSO}_{4}, 4.6 \mu \mathrm{M} \mathrm{H}_{3} \mathrm{BO}_{3}$, $0.5 \mu \mathrm{M}$ solution of $\mathrm{MnCl}_{2}, 0.2 \mu \mathrm{M}$ solution of $\mathrm{ZnSO}_{4}$, $0.1 \mu \mathrm{M}$ solution of $\mathrm{Na}_{2} \mathrm{MoO}_{4}, 0.2 \mu \mathrm{M}$ solution of $\mathrm{CuSO}_{4}$, $45 \mu \mathrm{M} \mathrm{Na} \mathrm{N}_{2}$ EDTA, and $45 \mu \mathrm{M}$ solution of $\mathrm{FeSO}_{4}$. The $\mathrm{pH}$ was adjusted at 6.0 with $10 \mathrm{M} \mathrm{KOH}$. Aeration was supplied continuously through air pumps in the nutrient solution. The seedlings were grown in a fully controlled growth chamber at $(22.0 \pm 0.5){ }^{\circ} \mathrm{C}$, with a day/night cycle $16 / 8 \mathrm{~h}$ (photon flux of $150 \mu \mathrm{mol} \mathrm{m} \mathrm{m}^{-2} \mathrm{~s}^{-1}$ ) and the relative humidity of $65 \%$. After 10 days of treatment, plants were harvested and separated into leaves and roots. Leaves and roots of six randomly selected plants per treatment were weighed and taken to analysis.

\section{Chemicals}

Standards: BL (purity $>95 \%$ ), EBL (purity $>98 \%$ ), CS (purity $>95 \%$ ), 24-epicastasterone (ECS, purity $>98 \%$ ), CT (purity $>95 \%), 6 \mathrm{dCS}$ (purity $>98 \%$ ), 6dCT (purity $>90 \%$ ), TY (purity $>90 \%$ ), 6-deoxytyphasterol (6dTY, purity $>90 \%$ ), 28-homobrassinolide (HBL, purity $>95 \%)$ and stable isotope-labelled standards: $\left[{ }^{2} \mathrm{H}_{3}\right]$ brassinolide $\left(\mathrm{d}_{3}\right.$-BL, purity $\left.>95 \%\right)$ and $\left[{ }^{2} \mathrm{H}_{3}\right]$ castasterone $\left(\mathrm{d}_{3}-\mathrm{CS}\right.$, purity $\left.>94 \%\right)$ were purchased from OlChemIm s.r.o. (Olomouc, Czech Republic). Brz (purity $>93 \%$ ) was purchased from TCI Europe N.V. (Zwijndrecht, Belgium). Acetonitrile (ACN), methanol $(\mathrm{MeOH})$ and water (LC-MS grade), $\mathrm{KOH}$ and formic acid (FA) were purchased from Merck KGaA (Darmstadt, Germany). All reagents used to Hoagland solution were purchased from Sigma-Aldrich (St. Louis, USA). All solutions were prepared in ultrapure water (LC-MS grade). A solution of $10 \mu \mathrm{M}$ EBL was prepared from $0.1 \mathrm{mM}$ EBL stock dissolved in $70 \% \mathrm{EtOH}$. Brz was also dissolved in $70 \% \mathrm{EtOH}$. Weaker solutions of EBL and Brz were prepared by serial dilution. An equal amount of EtOH was added to the control. The final EtOH concentration in the culture medium did not exceed $0.25 \%$, and this concentration did not affect the growth of seedlings.

\section{Quantitative analysis of brassinosteroids}

Plant tissues ( $0.1 \mathrm{~g}$ fresh weight (FW) of leaves or roots) were frozen in liquid nitrogen and ground into fine powder with a mortar and a pestle and then transferred into a 2-mL Eppendorf Protein LoBind PCR clean tube. The tissues were resuspended in $1 \mathrm{~mL} \mathrm{MeOH}$ and homogenised in bead mill $(50 \mathrm{~Hz}, 5 \mathrm{~min}$; TissueLyser LT, Qiagen, Germany) using two $3 \mathrm{~mm}$ zirconium balls. The homogenates were centrifuged $(9000 \times g, 5 \mathrm{~min}$; MPW-55 Med. Instruments, Poland). This process was repeated five times. The homogenates $(5 \mathrm{~mL})$ were collected in $25 \mathrm{~mL}$ glass flask, and then the samples were mixed $\left(90 \mathrm{rpm}\right.$, dark, $5{ }^{\circ} \mathrm{C}$, $12 \mathrm{~h}$; Laboratory shaker LC-350, Pol-Eko-Aparatura sp. J., Poland). For quantification of BRs, $\mathrm{d}_{3}$-BL (2 ng) and $\mathrm{d}_{3}$-CS (2 $\mathrm{ng}$ ) were added into the mixture followed by extraction with $\mathrm{MeOH}$ as internal standards. For screening of BRs, no internal standards were added. After extraction, plant particles were separated by centrifugation $(9000 \times g$, 5 min).

The endogenous BR level was determined using LC-QTOF-MS via sample preparation with ion exchange solid-phase extraction (SPE) (Xin et al. 2013). Oasis MAX cartridge ( $6 \mathrm{~mL}, 500 \mathrm{mg}$; Waters, Milford, USA) was activated and equilibrated with $\mathrm{MeOH}$, water, $1 \mathrm{M}$ 
$\mathrm{KOH}, 10 \%(\mathrm{v} / \mathrm{v}) \mathrm{MeOH}$ and $95 \%(\mathrm{v} / \mathrm{v}) \mathrm{MeOH}$ in turn. The next, Oasis MCX cartridge $(6 \mathrm{~mL}, 500 \mathrm{mg}$; Waters, Milford, USA) was activated and equilibrated with $\mathrm{MeOH}$, water, $5 \%(\mathrm{v} / \mathrm{v}) \mathrm{FA}$ and $10 \%(\mathrm{v} / \mathrm{v}) \mathrm{MeOH}$ in turn. Then, the crude plant extracts were passed through a MAX cartridge and collected to be dried by centrifugal evaporator (CentriVap ${ }^{\circledR}$ IR Vacuum Centrifugal Concentrators, Labconco Corp., USA). The samples were dissolved in $4 \mathrm{~mL}$ of $10 \% \mathrm{MeOH}$ and passed through a MCX cartridge. After sequential washing with 5\% (v/v) FA in 5\% (v/v) MeOH, $5 \%(\mathrm{v} / \mathrm{v}) \mathrm{MeOH}, 5 \%(\mathrm{v} / \mathrm{v}) \mathrm{NH}_{4} \mathrm{OH}$ in $5 \%(\mathrm{v} / \mathrm{v}) \mathrm{MeOH}$ and $5 \%(\mathrm{v} / \mathrm{v}) \mathrm{MeOH}, \mathrm{BRs}$ were eluted with $80 \%$ (v/v) $\mathrm{MeOH}$. The elution was dried and then dissolved in $98 \mu \mathrm{L}$ of EtOH to be derivatised with $2 \mu \mathrm{L} 4$-(dimethylamino) phenylboronic acid (DMAPBA) $\left(1 \mathrm{~h}, 45^{\circ} \mathrm{C}\right)$. Finally, the obtained samples were transferred to HPLC vials with inserts.

Detection of BR-DMAPBA was performed on the Agilent 1260 Infinity series HPLC system (Agilent Technologies, USA) consisting of a degasser, binary pump, autosampler and column oven combined with 6540 UHD Accurate-Mass Q-TOF LC/MS (Agilent Technologies, USA) mass spectrometer with Dual AJS ESI source.

Each sample $(10 \mu \mathrm{L})$ was injected onto a XBridge $\mathrm{C}_{18}$ column $(250 \mathrm{~mm} \times 4.6 \mathrm{~mm}, 1.7 \mu \mathrm{m})$. The column temperature was held at $25{ }^{\circ} \mathrm{C}$. The inlet method was set as follows: mobile phase A, $0.1 \%$ (v/v) FA in water and B, $0.1 \%$ (v/v) FA in ACN. Gradient was as follows: $0-2$ min, 75\% B; 2-14 min, 85\% B; 14-40 min, 95\% B; 40-42 min, 75\% $\mathrm{B}$; and $42-45 \mathrm{~min}, 75 \% \mathrm{~B}$. The separation at a flow rate of $0.2 \mathrm{~mL} \mathrm{~min}^{-1}$ was employed. The MS parameters were optimised with mixture of standard solutions ESI Tuning Mix (Agilent Technologies, USA). Nitrogen was used not only as a nebulizer but also as drying and collision gas. The nebulizer gas pressure, drying gas pressure, curtain gas pressure, source voltage and source temperature were set at $60 \mathrm{psi}, 50 \mathrm{psi}, 30 \mathrm{psi}, 3.5 \mathrm{kV}$ and $350{ }^{\circ} \mathrm{C}$, respectively. Spectra were acquired by summarizing 5000 single spectra. Full scan mode was used. Extraction of centroid spectra peaks with a width of $0.01 \mathrm{Da}$ was used to pick up the extracted ion chromatograms from the total ion chromatogram. BRs and their corresponding internal standards were analysed in the positive-ion mode. Instrument control and data processing were carried out by Agilent MassHunter Workstation Software for LC/MS.

Analyte recovery was calculated as the ratio of the mean peak area of an unlabelled analyte, spiked before SPE purification, to the mean peak area of the same analyte, spiked after SPE purification, multiplied by 100 and finally expressed in percentage (Caban et al. 2012). The average recovery for each determined BR was as follows: $85 \%$ for BL, $84 \%$ for $6 \mathrm{dTY}, 83 \%$ for EBL and 6dCS, $82 \%$ for CT, $81 \%$ for CS and TY, $80 \%$ for ECS and $78 \%$ for HBL.

\section{Statistics}

Each treatment consisted of two replicates and each experiment was carried out at least four times at different points $(n=8)$. Basic descriptive statistical analysis was performed using R (R Core Team 2018). The data were further assessed for normality and homogeneity of variances using the Shapiro-Wilk test ['stats' package (R Core Team 2018)] and Levene's test ['car' package (Fox and Weisberg 2011)], respectively. The one-way ANOVA ['stats' package (R Core Team 2018)] and Tukey's post hoc test ['laercio' package (da Silva 2010)] were used to group compounds based on their average amount. Differences were considered statistically significant at $p<0.05$.

\section{Results}

Barley cv. Golden Promise seedlings treated with Brz, EBL, combinations of Brz and EBL are presented in Fig. 1. Brztreated seedlings showed limited growth in a concentrationdependent manner from 0.1 to $10 \mu \mathrm{M}$ (Fig. 1a). Application of EBL alone caused a slight stimulation of seedling growth at $0.1 \mu \mathrm{M}$ (Fig. 1b). In plants treated with $0.001 \mu \mathrm{M}$ and $0.01 \mu \mathrm{M}$ EBL, the phenotype was very similar to that of the control. Moreover, the retarding effect of the Brz on the elongation of barley seedlings was negated by the application of the EBL (Fig. 1c-d).

Brz treatment did not affect the growth of roots and they were comparable to the control. Similar results were obtained when the mixtures of Brz and EBL were applied. However, a slight inhibition of the root growth was noted in plants treated with EBL at $1 \mu \mathrm{M}$ or higher concentration (Fig. 1b).

A LC-QTOF-MS analysis of barley cv. Golden Promise led to the detection of nine known BRs, i.e. BL, EBL, HBL, CS, ECS, CT, TY 6dTY and 6dCS both in the leaves (Table 1) and roots (Table 2). The presence of these compounds in barley cv. Golden Promise is reported for the first time (Table 3). The highest level of BRs was detected in the leaves, i.e. BL and CT $\left(2.98,2.25 \mathrm{ng} \mathrm{g}^{-1} \mathrm{FW}\right.$, respectively). Furthermore, the highest content of CS, CT and $6 \mathrm{dTY}$ was noted in the roots $\left(1.38,1.05,0.19 \mathrm{ng} \mathrm{g}^{-1} \mathrm{FW}\right.$, respectively). Trace amounts ( $<1 \%$ of all BRs) of HBL and ECS were detected in the leaves; EBL in roots. Total amount of BRs was higher in the leaves $\left(6.69 \mathrm{ng} \mathrm{g}^{-1} \mathrm{FW}\right)$ than roots (2.93 $\left.\mathrm{ng} \mathrm{g}^{-1} \mathrm{FW}\right)$.

The influence of different treatments on BR accumulation in barley leaves was investigated (Fig. 2, Table 1). According to the results, the application of $\mathrm{Brz}(0.1-10 \mu \mathrm{M})$ significantly decreased the content of BRs $(p<0.05)$ (Fig. 2a). The content of BRs decreased gradually with the increasing concentrations of Brz, reaching the lowest level in 

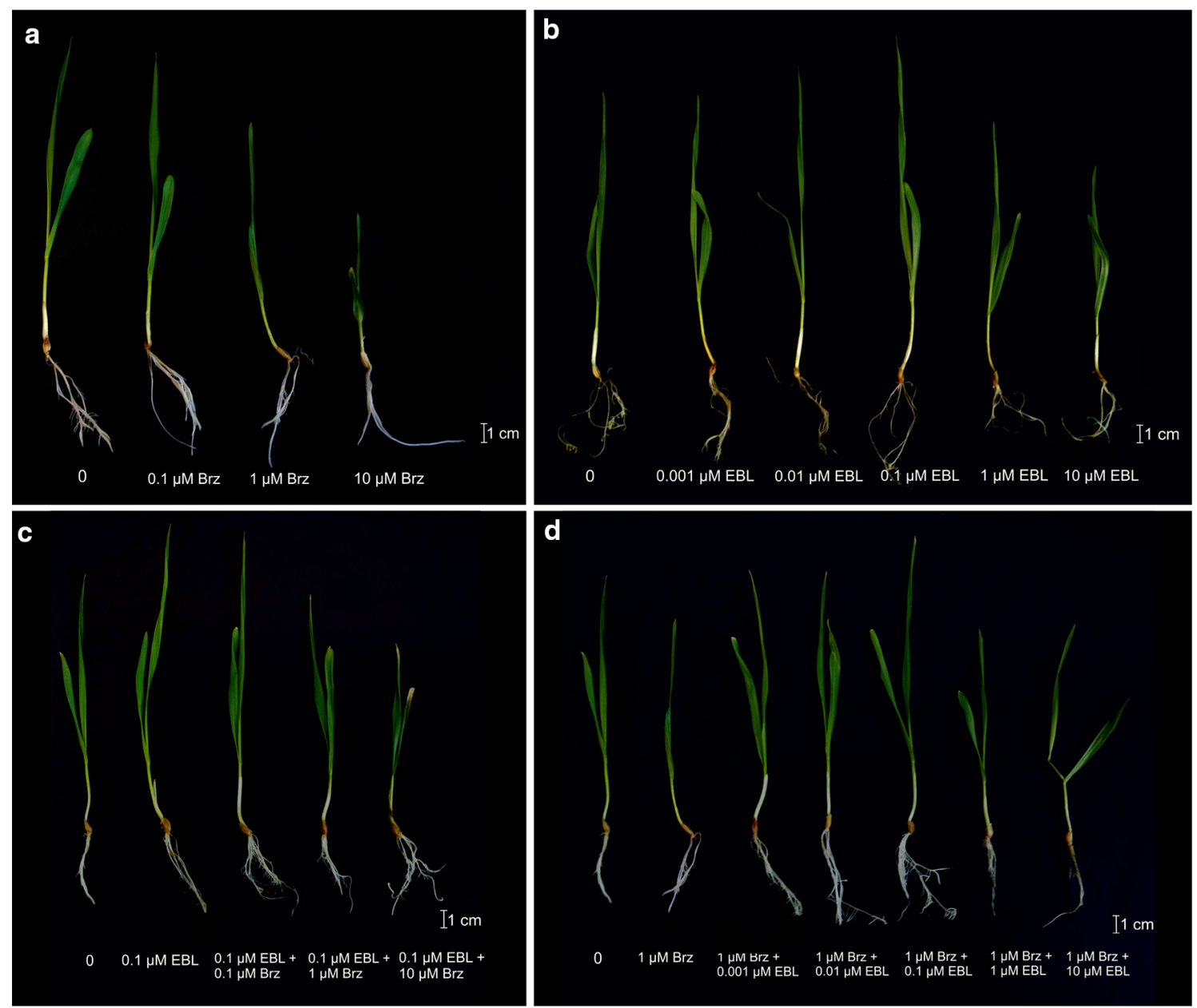

Fig. 1 Phenotypes of 14-day-old de-etiolated barley Golden Promise seedlings treated with: (a) brassinazole (Brz), (b) 24-epibrassinolide (EBL), c, d Brz and/or EBL vs. control. Scale bar, $1 \mathrm{~cm}$

seedlings treated with $10 \mu \mathrm{M} \mathrm{Brz}$ in relation to the control. For example, the content of BL decreased by $81 \%$ compared to untreated seedlings. In the range of concentrations $0.001-0.1 \mu \mathrm{M}$, the EBL had a stimulatory effect on the content of BRs in the leaves. However, the 1-10 $\mu \mathrm{M}$ EBL had an opposite effect, i.e. ECS, EBLS, HBL, 6dTY and 6dCS had not been detected in plants treated with $10 \mu \mathrm{M}$ EBL (Fig. 2b).

Application of $0.1 \mu \mathrm{M}$ EBL had a slightly stimulatory effect on synthesis of BL and CS in seedlings treated with $0.1 \mu \mathrm{M}$ Brz. Combination of $0.1 \mu \mathrm{M}$ EBL and $1 \mu \mathrm{M} \mathrm{Brz}$ caused a slight decrease of CT, EBL, TY, 6dTY and 6dCS contents in relation to the control. However, in plants treated with $1 \mu \mathrm{M}$ EBL and $10 \mu \mathrm{M} \mathrm{Brz}$ at least $30 \%$ decrease in BR content was reported (Fig. 2c, Table 1). Inhibition effect of $1 \mu \mathrm{M}$ Brz on the BR content was restored by application of EBL at the range of concentrations $0.001-1 \mu \mathrm{M}$. In seedlings treated with the mixture of $1 \mu \mathrm{M} \mathrm{Brz}$ and $0.1 \mu \mathrm{M}$ EBL the content of BRs was very similar to the control (Fig. 2d).
Total inhibition of synthesis of ECS, HBL and 6dCS was noted in plants treated with $10 \mu \mathrm{M}$ Brz and this effect had not been restored by the application of EBL (Table 1).

In opposite to what was observed in the leaves, the Brz treatment in the range of concentration from 0.1 to $1 \mu \mathrm{M}$ did not exert significant influence on the content of BRs in the roots. However, the highest $10 \mu \mathrm{M}$ concentration of Brz led to the decreased BR content (Fig. 3a).

The effect of EBL in the range $0.001-10 \mu \mathrm{M}$ on the BR content is shown in Table 2 and Fig. 3b. A significant $(p<0.05)$ increase was found after application of $0.1 \mu \mathrm{M}$ EBL. By contrast, treatment with 1-10 $\mu \mathrm{M}$ EBL resulted in inhibition of BR accumulation compared to the control or other EBL concentrations. However, the EBL treatment in 0.001-0.01 $\mu \mathrm{M}$ did not alter the endogenous levels of BRs, which were very similar to those of the control.

Addition of different combination of Brz and EBL concentrations overcame the inhibitory effect of Brz. The most effective on the content of BRs was a mixture of $0.1 \mu \mathrm{M}$ EBL 
Table 1 Endogenous content of brassinosteroids in barley leaves treated with brassinazole and/or 24-epibrassinolide

\begin{tabular}{|c|c|c|c|}
\hline \multirow[t]{2}{*}{ Treatment } & \multicolumn{3}{|c|}{ Brassinosteroid (ng g ${ }^{-1}$ fresh weight) } \\
\hline & $\mathrm{CS}$ & ECS & $\mathrm{BL}$ \\
\hline 0 & $1.01 \pm 0.0142^{d e}$ & $0.012 \pm 0.0002^{f}$ & $2.983 \pm 0.0884^{e}$ \\
\hline $0.1 \mu \mathrm{M} \mathrm{Brz}$ & $0.859 \pm 0.0058^{f}$ & $0.008 \pm 0.0004^{g}$ & $2.631 \pm 0.1369^{g}$ \\
\hline $1 \mu \mathrm{M} \mathrm{Brz}$ & $0.544 \pm 0.0202^{j}$ & $0.005 \pm 0.0001^{h}$ & $1.655 \pm 0.0442^{j}$ \\
\hline $10 \mu \mathrm{M} \mathrm{Brz}$ & $0.39 \pm 0.0074^{k}$ & nd & $0.565 \pm 0.0061^{l}$ \\
\hline $0.001 \mu \mathrm{M}$ EBL & $1.055 \pm 0.0537^{d}$ & $0.031 \pm 0.0002^{e}$ & $3.179 \pm 0.0621^{c d}$ \\
\hline $0.01 \mu \mathrm{M}$ EBL & $1.245 \pm 0.0173^{c}$ & $0.067 \pm 0.0029^{c}$ & $3.686 \pm 0.1126^{b}$ \\
\hline $0.1 \mu \mathrm{M} \mathrm{EBL}$ & $2.053 \pm 0.0371^{a}$ & $0.136 \pm 0.0033^{a}$ & $4.215 \pm 0.042^{a}$ \\
\hline $1 \mu \mathrm{M} \mathrm{EBL}$ & $1.568 \pm 0.0422^{b}$ & $0.058 \pm 0.0006^{d}$ & $2.789 \pm 0.1479^{f g}$ \\
\hline $10 \mu \mathrm{M}$ EBL & $0.752 \pm 0.0112^{h}$ & nd & $0.946 \pm 0.0142^{k}$ \\
\hline $0.1 \mu \mathrm{M} \mathrm{EBL}+0.1 \mu \mathrm{M} \mathrm{Brz}$ & $1.529 \pm 0.0605^{b}$ & $0.087 \pm 0.0009^{b}$ & $3.187 \pm 0.0268^{c}$ \\
\hline $0.1 \mu \mathrm{M} \mathrm{EBL}+1 \mu \mathrm{M} \mathrm{Brz}$ & $0.986 \pm 0.0369^{e}$ & nd & $3.012 \pm 0.0902^{d e}$ \\
\hline $0.1 \mu \mathrm{M} \mathrm{EBL}+10 \mu \mathrm{M} \mathrm{Brz}$ & $0.452 \pm 0.0142^{k}$ & nd & $2.184 \pm 0.0618^{i}$ \\
\hline $1 \mu \mathrm{M} \mathrm{Brz}+0.001 \mu \mathrm{M}$ EBL & $0.768 \pm 0.0227^{g h}$ & nd & $2.424 \pm 0.0191^{h}$ \\
\hline $1 \mu \mathrm{M} \mathrm{Brz}+0.01 \mu \mathrm{M} \mathrm{EBL}$ & $0.834 \pm 0.0114^{f g}$ & nd & $2.853 \pm 0.0248^{e f}$ \\
\hline $1 \mu \mathrm{M} \mathrm{Brz}+0.1 \mu \mathrm{M} \mathrm{EBL}$ & $0.986 \pm 0.0369^{e}$ & nd & $3.012 \pm 0.0902^{d e}$ \\
\hline $1 \mu \mathrm{M} \mathrm{Brz}+1 \mu \mathrm{M} \mathrm{EBL}$ & $0.728 \pm 0.0293^{h}$ & nd & $1.757 \pm 0.0512^{j}$ \\
\hline $1 \mu \mathrm{M} \mathrm{Brz}+10 \mu \mathrm{M} \mathrm{EBL}$ & $0.658 \pm 0.0146^{i}$ & nd & $1.628 \pm 0.0486^{j}$ \\
\hline \multirow[t]{2}{*}{ Treatment } & \multicolumn{3}{|c|}{ Brassinosteroid (ng $\mathrm{g}^{-1}$ fresh weight) } \\
\hline & EBL & HBL & $\mathrm{CT}$ \\
\hline 0 & $0.125 \pm 0.0007^{c}$ & $0.04 \pm 0.0012^{e}$ & $2.247 \pm 0.0145^{c}$ \\
\hline $0.1 \mu \mathrm{M} \mathrm{Brz}$ & $0.091 \pm 0.0007^{e}$ & $0.033 \pm 0.0003^{g}$ & $1.587 \pm 0.0613^{e}$ \\
\hline $1 \mu \mathrm{M} \mathrm{Brz}$ & $0.049 \pm 0.0012^{i}$ & $0.017 \pm 0.0001^{h}$ & $1.143 \pm 0.0168^{g h}$ \\
\hline $10 \mu \mathrm{M} \mathrm{Brz}$ & $0.018 \pm 0.0007^{j}$ & nd & $0.504 \pm 0.0033^{i}$ \\
\hline $0.001 \mu \mathrm{M}$ EBL & $0.121 \pm 0.0007^{c}$ & $0.043 \pm 0.0004^{d}$ & $2.362 \pm 0.0713^{b c}$ \\
\hline $0.01 \mu \mathrm{M} \mathrm{EBL}$ & $0.176 \pm 0.0055^{b}$ & $0.08 \pm 0.0017^{b}$ & $2.461 \pm 0.0182^{b}$ \\
\hline $0.1 \mu \mathrm{M}$ EBL & $0.353 \pm 0.0067^{a}$ & $0.176 \pm 0.0019^{a}$ & $2.994 \pm 0.1573^{a}$ \\
\hline $1 \mu \mathrm{M} \mathrm{EBL}$ & $0.102 \pm 0.003^{d}$ & $0.036 \pm 0.0007^{f}$ & $1.376 \pm 0.0542^{f}$ \\
\hline $10 \mu \mathrm{M}$ EBL & nd & nd & $1.104 \pm 0.0511^{h}$ \\
\hline $0.1 \mu \mathrm{M} \mathrm{EBL}+0.1 \mu \mathrm{M} \mathrm{Brz}$ & $0.122 \pm 0.0039^{c}$ & $0.074 \pm 0.0017^{c}$ & $2.277 \pm 0.0415^{c}$ \\
\hline $0.1 \mu \mathrm{M} \mathrm{EBL}+1 \mu \mathrm{M} \mathrm{Brz}$ & $0.093 \pm 0.0012^{e}$ & nd & $2.009 \pm 0.057^{d}$ \\
\hline $0.1 \mu \mathrm{M} \mathrm{EBL}+10 \mu \mathrm{M} \mathrm{Brz}$ & nd & nd & $1.257 \pm 0.0323^{f g}$ \\
\hline $1 \mu \mathrm{M} \mathrm{Brz}+0.001 \mu \mathrm{M}$ EBL & $0.056 \pm 0.0014^{h}$ & nd & $1.371 \pm 0.0687^{f}$ \\
\hline $1 \mu \mathrm{M} \mathrm{Brz}+0.01 \mu \mathrm{M} \mathrm{EBL}$ & $0.071 \pm 0.0022^{f g}$ & nd & $1.709 \pm 0.0844^{e}$ \\
\hline $1 \mu \mathrm{M} \mathrm{Brz}+0.1 \mu \mathrm{M} \mathrm{EBL}$ & $0.093 \pm 0.0012^{e}$ & nd & $2.009 \pm 0.057^{d}$ \\
\hline $1 \mu \mathrm{M} \mathrm{Brz}+1 \mu \mathrm{M} \mathrm{EBL}$ & $0.075 \pm 0.0007^{f}$ & nd & $1.276 \pm 0.0659^{f g}$ \\
\hline $1 \mu \mathrm{M} \mathrm{Brz}+10 \mu \mathrm{M} \mathrm{EBL}$ & $0.069 \pm 0.0007^{g}$ & nd & $1.146 \pm 0.047^{g h}$ \\
\hline \multirow[t]{2}{*}{ Treatment } & \multicolumn{3}{|c|}{ Brassinosteroid (ng $\mathrm{g}^{-1}$ fresh weight) } \\
\hline & TY & $6 \mathrm{dTY}$ & $6 \mathrm{dCS}$ \\
\hline 0 & $0.075 \pm 0.0016^{g}$ & $0.074 \pm 0.0005^{c}$ & $0.122 \pm 0.003^{e}$ \\
\hline $0.1 \mu \mathrm{M} \mathrm{Brz}$ & $0.062 \pm 0.0004^{h}$ & $0.027 \pm 0.0007^{g}$ & $0.109 \pm 0.0027^{f}$ \\
\hline $1 \mu \mathrm{M} \mathrm{Brz}$ & $0.048 \pm 0.002^{i j}$ & $0.015 \pm 0.0002^{h}$ & $0.046 \pm 0.0011^{i}$ \\
\hline $10 \mu \mathrm{M} \mathrm{Brz}$ & $0.022 \pm 0.0006^{k}$ & $0.009 \pm 0.0001^{i}$ & nd \\
\hline $0.001 \mu \mathrm{M}$ EBL & $0.096 \pm 0.0008^{e}$ & $0.069 \pm 0.0031^{d}$ & $0.132 \pm 0.0049^{d}$ \\
\hline $0.01 \mu \mathrm{M}$ EBL & $0.181 \pm 0.0071^{b}$ & $0.122 \pm 0.0016^{b}$ & $0.173 \pm 0.0032^{b}$ \\
\hline $0.1 \mu \mathrm{M}$ EBL & $0.317 \pm 0.0095^{a}$ & $0.178 \pm 0.0072^{a}$ & $0.216 \pm 0.0064^{a}$ \\
\hline $1 \mu \mathrm{M} \mathrm{EBL}$ & $0.121 \pm 0.0031^{c}$ & nd & nd \\
\hline
\end{tabular}


Table 1 (continued)

\begin{tabular}{|c|c|c|c|}
\hline \multirow[t]{2}{*}{ Treatment } & \multicolumn{3}{|c|}{ Brassinosteroid (ng $\mathrm{g}^{-1}$ fresh weight) } \\
\hline & TY & $6 \mathrm{dTY}$ & $6 \mathrm{dCS}$ \\
\hline $10 \mu \mathrm{M}$ EBL & $0.079 \pm 0.001^{f g}$ & nd & nd \\
\hline $0.1 \mu \mathrm{M} \mathrm{EBL}+0.1 \mu \mathrm{M} \mathrm{Brz}$ & $0.109 \pm 0.0028^{d}$ & $0.048 \pm 0.0009^{e}$ & $0.146 \pm 0.0055^{c}$ \\
\hline $0.1 \mu \mathrm{M} \mathrm{EBL}+1 \mu \mathrm{M} \mathrm{Brz}$ & $0.084 \pm 0.0036^{f}$ & $0.037 \pm 0.0009^{f}$ & $0.087 \pm 0.002^{g}$ \\
\hline $0.1 \mu \mathrm{M} \mathrm{EBL}+10 \mu \mathrm{M} \mathrm{Brz}$ & nd & nd & nd \\
\hline $1 \mu \mathrm{M} \mathrm{Brz}+0.001 \mu \mathrm{M} \mathrm{EBL}$ & $0.048 \pm 0.0011^{i j}$ & $0.028 \pm 0.0005^{g}$ & $0.052 \pm 0.0015^{i}$ \\
\hline $1 \mu \mathrm{M} \mathrm{Brz}+0.01 \mu \mathrm{M} \mathrm{EBL}$ & $0.054 \pm 0.0016^{i}$ & $0.031 \pm 0.0008^{g}$ & $0.072 \pm 0.0005^{h}$ \\
\hline $1 \mu \mathrm{M} \mathrm{Brz}+0.1 \mu \mathrm{M} \mathrm{EBL}$ & $0.084 \pm 0.0036^{f}$ & $0.037 \pm 0.0009^{f}$ & $0.087 \pm 0.002^{g}$ \\
\hline $1 \mu \mathrm{M} \mathrm{Brz}+1 \mu \mathrm{M}$ EBL & $0.065 \pm 0.0027^{h}$ & nd & nd \\
\hline $1 \mu \mathrm{M} \mathrm{Brz}+10 \mu \mathrm{M} \mathrm{EBL}$ & $0.044 \pm 0.0005^{j}$ & nd & nd \\
\hline
\end{tabular}

Data represent the mean $(n=8) \pm$ standard deviation (SD). Means \pm SD connected by the same letter are not significantly different $(p \geq 0.05)$ according to Tukey's post hoc test; data were grouped according to treatments of each compound

nd not detected

with $1 \mu \mathrm{M}$ Brz. Furthermore, plants treated with $0.1 \mu \mathrm{M}$ EBL and $10 \mu \mathrm{M}$ Brz had higher level of 6dTY compared to the control and plants treated with $0.1 \mu \mathrm{M}$ EBL alone. The combination of $0.1 \mu \mathrm{M}$ EBL and $0.1 \mu \mathrm{M}$ Brz appeared not to affect the BR level as compared to the control. Application of $1-10 \mu \mathrm{M}$ EBL and $1 \mu \mathrm{M}$ Brz had no influence on the endogenous content of BRs. However, combined treatment with $0.001-0.01 \mu \mathrm{M}$ EBL and $1 \mu \mathrm{M}$ Brz appeared to have a stimulatory effect on the BR content as compared to the control and seedlings treated with $1 \mu \mathrm{M}$ Brz alone.

\section{Discussion}

BRs are commonly found in plants at very low concentrations. The presence of BRs has been confirmed both in monocotyledonous and dicotyledonous, as well as in algae, pteridophytes, gymnosperms. The largest amounts of BRs are present in the generative parts of plants, e.g. in pollen, fruits and seeds, but in fact the amount of BR varies considerably, and it may depend on the species and even the variety. The content of BRs in stems is in the range of $0.12-2 \mathrm{ng} \mathrm{g}^{-1} \mathrm{FW}$; however, in roots the levels are one magnitude lower, i.e. $0.05 \mathrm{ng} \mathrm{g}^{-1} \mathrm{FW}$ (Bajguz and Tretyn 2003).

In plants of the Poaceae family, BRs have been found so far in rice (Oryza sativa) (Abe et al. 1984, 1995; Park et al. 1994; Suzuki et al. 1995; Wu et al. 2008; Asahina et al. 2014), maize (Zea mays) (Gamoh et al. 1990; Suzuki et al. 1986; Kim et al. 2005), wheat (Triticum aestivum) (Yokota et al. 1994; Janeczko et al. 2010; Janeczko and Swaczynova 2010), rye (Secale cereale) (Schmidt et al. 1995; Antonchick et al. 2003, 2005), barley (Janeczko et al. 2011; Dockter et al. 2014) as well as in canary grass (Phalaris canariensis) (Shimada et al. 1996) and perennial ryegrass (Lolium perenne) (Taylor et al. 1993).
There are significant differences between types of BRs and their concentrations in different cereal species. The most widely distributed BRs in Poaceae are CS, BL, TY, 6dTY, TE and 6dTE. The levels and the profiles of BRs in Poaceae vary and there are many factors that modify them. Differences have been found between individual families, plant species and cultivars as well as between plant organs (Asahina et al. 2014). Recent reports showed that few BRs have been identified in leaves of barley cultivars, i.e. BL, CS in cv. Sezam (Janeczko et al. 2011); CS, EBL and 28-homocastasterone (HCS) in cv. Bowman (Dockter et al. 2014; Gruszka et al. 2016a); CS in cv. Delisa (Gruszka et al. 2016b). In the present study, we detected more BRs, i.e. BL, EBL, HBL, CS, ECS, CT, TY 6dTY and 6dCS both in the leaves and roots of cv. Golden Promise. The three BL, CT and CS are dominating in leaves, while the two CS and CT in roots. The present work revealed that some of the early and the late C-6 oxidation pathway metabolites were also detected. Because some of the BRs have not been analysed yet, i.e. 6dCT, 6dTE, 6-deoxo-3DT, TE and 3DT, there is no evidence which pathway is dominating in leaves and in roots. However, the results showed that the biosynthetic pathways of BRs also operate in barley seedlings of cv. Golden Promise.

It is known that bioactive BRs can be inactivated via different reactions including hydroxylation, glycosylation, sulfonation, demethylation, epimerization, esterification, dehydrogenation and side-chain cleavage at multiple positions (Bajguz 2007). Present results showed that two epimers of BRs, i.e. EBL and ECS, were present in trace amounts. In the future, additional investigation will be required to reveal next downstream metabolites of BR biosynthetic pathways in this plant.

BRs regulate many aspects of plant growth and development. To examine the occurrence and functions of endogenous BRs in barley seedlings, we tested the action of the 
Table 2 Endogenous content of brassinosteroids in barley roots treated with brassinazole and/or 24-epibrassinolide

\begin{tabular}{|c|c|c|c|}
\hline \multirow[t]{2}{*}{ Treatment } & \multicolumn{3}{|c|}{ Brassinosteroid (ng $\mathrm{g}^{-1}$ fresh weight) } \\
\hline & $\mathrm{CS}$ & ECS & $\mathrm{BL}$ \\
\hline 0 & $1.38 \pm 0.0348^{d e}$ & $0.057 \pm 0.0024^{d}$ & $0.043 \pm 0.0004^{g}$ \\
\hline $0.1 \mu \mathrm{M} \mathrm{Brz}$ & $1.379 \pm 0.0669^{d e}$ & $0.057 \pm 0.0005^{d}$ & $0.043 \pm 0.0023^{g}$ \\
\hline $1 \mu \mathrm{M} \mathrm{Brz}$ & $1.380 \pm 0.0221^{d e}$ & $0.056 \pm 0.0025^{d}$ & $0.043 \pm 0.0014^{g}$ \\
\hline $10 \mu \mathrm{M} \mathrm{Brz}$ & $1.102 \pm 0.0386^{f}$ & $0.034 \pm 0.0018^{f}$ & $0.028 \pm 0.0015^{h}$ \\
\hline $0.001 \mu \mathrm{M}$ EBL & $1.372 \pm 0.0654^{e}$ & $0.056 \pm 0.0012^{d}$ & $0.043 \pm 0.0023^{g}$ \\
\hline $0.01 \mu \mathrm{M}$ EBL & $1.381 \pm 0.0513^{d e}$ & $0.057 \pm 0.0031^{d}$ & $0.041 \pm 0.0013^{g}$ \\
\hline $0.1 \mu \mathrm{M} \mathrm{EBL}$ & $1.528 \pm 0.057^{b c}$ & $0.072 \pm 0.0031^{b}$ & $0.070 \pm 0.003^{d}$ \\
\hline $1 \mu \mathrm{M} \mathrm{EBL}$ & $1.113 \pm 0.0077^{f}$ & $0.028 \pm 0.0012^{g}$ & $0.029 \pm 0.0002^{h}$ \\
\hline $10 \mu \mathrm{M}$ EBL & $0.985 \pm 0.0161^{g}$ & $0.012 \pm 0.0001^{h}$ & $0.015 \pm 0.0006^{i}$ \\
\hline $0.1 \mu \mathrm{M} \mathrm{EBL}+0.1 \mu \mathrm{M} \mathrm{Brz}$ & $1.361 \pm 0.0108^{e}$ & $0.042 \pm 0.0009^{e}$ & $0.041 \pm 0.0003^{g}$ \\
\hline $0.1 \mu \mathrm{M} \mathrm{EBL}+1 \mu \mathrm{M} \mathrm{Brz}$ & $1.689 \pm 0.0128^{a}$ & $0.082 \pm 0.0018^{a}$ & $0.098 \pm 0.0021^{a}$ \\
\hline $0.1 \mu \mathrm{M} \mathrm{EBL}+10 \mu \mathrm{M} \mathrm{Brz}$ & $1.458 \pm 0.0375^{c d}$ & $0.064 \pm 0.0025^{c}$ & $0.082 \pm 0.0018^{b}$ \\
\hline $1 \mu \mathrm{M} \mathrm{Brz}+0.001 \mu \mathrm{M} \mathrm{EBL}$ & $1.442 \pm 0.0367^{d e}$ & $0.062 \pm 0.0013^{c}$ & $0.058 \pm 0.0032^{e}$ \\
\hline $1 \mu \mathrm{M} \mathrm{Brz}+0.01 \mu \mathrm{M} \mathrm{EBL}$ & $1.561 \pm 0.0109^{b}$ & $0.078 \pm 0.0032^{a}$ & $0.076 \pm 0.0025^{c}$ \\
\hline $1 \mu \mathrm{M} \mathrm{Brz}+0.1 \mu \mathrm{M} \mathrm{EBL}$ & $1.689 \pm 0.0128^{a}$ & $0.082 \pm 0.0018^{a}$ & $0.098 \pm 0.0021^{a}$ \\
\hline $1 \mu \mathrm{M} \mathrm{Brz}+1 \mu \mathrm{M} \mathrm{EBL}$ & $1.410 \pm 0.0374^{d e}$ & $0.063 \pm 0.0031^{c}$ & $0.049 \pm 0.001^{f}$ \\
\hline $1 \mu \mathrm{M} \mathrm{Brz}+10 \mu \mathrm{M} \mathrm{EBL}$ & $1.395 \pm 0.011^{d e}$ & $0.059 \pm 0.0026^{c d}$ & $0.044 \pm 0.0004^{f g}$ \\
\hline \multirow[t]{2}{*}{ Treatment } & \multicolumn{3}{|c|}{ Brassinosteroid (ng g ${ }^{-1}$ fresh weight) } \\
\hline & EBL & HBL & $\mathrm{CT}$ \\
\hline 0 & $0.009 \pm 0.0002^{d}$ & $0.123 \pm 0.0022^{f}$ & $1.053 \pm 0.0487^{d e}$ \\
\hline $0.1 \mu \mathrm{M} \mathrm{Brz}$ & $0.009 \pm 0.0004^{d e}$ & $0.123 \pm 0.003^{f}$ & $1.052 \pm 0.0381^{d e}$ \\
\hline $1 \mu \mathrm{M} \mathrm{Brz}$ & $0.009 \pm 0.0001^{d}$ & $0.123 \pm 0.0031^{f}$ & $1.051 \pm 0.0482^{d e}$ \\
\hline $10 \mu \mathrm{M} \mathrm{Brz}$ & $0.006 \pm 0.00004^{f}$ & $0.098 \pm 0.0008^{g}$ & $0.759 \pm 0.0114^{f}$ \\
\hline $0.001 \mu \mathrm{M}$ EBL & $0.009 \pm 0.0001^{d e}$ & $0.123 \pm 0.0016^{f}$ & $1.052 \pm 0.0173^{d e}$ \\
\hline $0.01 \mu \mathrm{M}$ EBL & $0.009 \pm 0.0001^{d e}$ & $0.123 \pm 0.0007^{f}$ & $1.052 \pm 0.0236^{d e}$ \\
\hline $0.1 \mu \mathrm{M}$ EBL & $0.012 \pm 0.0002^{c}$ & $0.198 \pm 0.0077^{b}$ & $1.214 \pm 0.0073^{b}$ \\
\hline $1 \mu \mathrm{M} \mathrm{EBL}$ & $0.008 \pm 0.0004^{e f}$ & $0.102 \pm 0.0007^{g}$ & $1.035 \pm 0.0469^{d e}$ \\
\hline $10 \mu \mathrm{M}$ EBL & $0.005 \pm 0.00004^{g}$ & $0.096 \pm 0.0023^{g}$ & $1.016 \pm 0.0451^{e}$ \\
\hline $0.1 \mu \mathrm{M} \mathrm{EBL}+0.1 \mu \mathrm{M} \mathrm{Brz}$ & $0.009 \pm 0.0003^{d e}$ & $0.118 \pm 0.001^{f}$ & $1.048 \pm 0.0061^{d e}$ \\
\hline $0.1 \mu \mathrm{M} \mathrm{EBL}+1 \mu \mathrm{M} \mathrm{Brz}$ & $0.034 \pm 0.0014^{a}$ & $0.225 \pm 0.0119^{a}$ & $1.354 \pm 0.0677^{a}$ \\
\hline $0.1 \mu \mathrm{M} \mathrm{EBL}+10 \mu \mathrm{M} \mathrm{Brz}$ & $0.021 \pm 0.0006^{b}$ & $0.189 \pm 0.0076^{b c}$ & $1.185 \pm 0.0079^{b c}$ \\
\hline $1 \mu \mathrm{M} \mathrm{Brz}+0.001 \mu \mathrm{M} \mathrm{EBL}$ & $0.012 \pm 0.0003^{c}$ & $0.154 \pm 0.0025^{d}$ & $1.072 \pm 0.0273^{d e}$ \\
\hline $1 \mu \mathrm{M} \mathrm{Brz}+0.01 \mu \mathrm{M} \mathrm{EBL}$ & $0.021 \pm 0.0009^{b}$ & $0.182 \pm 0.0093^{c}$ & $1.121 \pm 0.014^{c d}$ \\
\hline $1 \mu \mathrm{M} \mathrm{Brz}+0.1 \mu \mathrm{M} \mathrm{EBL}$ & $0.034 \pm 0.0014^{a}$ & $0.225 \pm 0.0119^{a}$ & $1.354 \pm 0.0677^{a}$ \\
\hline $1 \mu \mathrm{M} \mathrm{Brz}+1 \mu \mathrm{M} \mathrm{EBL}$ & $0.012 \pm 0.0005^{c}$ & $0.142 \pm 0.0073^{d e}$ & $1.075 \pm 0.0409^{d e}$ \\
\hline $1 \mu \mathrm{M} \mathrm{Brz}+10 \mu \mathrm{M} \mathrm{EBL}$ & $0.010 \pm 0.0001^{d}$ & $0.130 \pm 0.0055^{e f}$ & $1.068 \pm 0.0497^{d e}$ \\
\hline \multirow[t]{2}{*}{ Treatment } & \multicolumn{3}{|c|}{ Brassinosteroid (ng g ${ }^{-1}$ fresh weight) } \\
\hline & TY & 6dTY & 6dCS \\
\hline 0 & $0.038 \pm 0.0004^{e}$ & $0.186 \pm 0.0038^{f g}$ & $0.036 \pm 0.0007^{e}$ \\
\hline $0.1 \mu \mathrm{M} \mathrm{Brz}$ & $0.037 \pm 0.002^{e}$ & $0.186 \pm 0.0026^{f g}$ & $0.036 \pm 0.002^{e}$ \\
\hline $1 \mu \mathrm{M} \mathrm{Brz}$ & $0.038 \pm 0.0016^{e}$ & $0.186 \pm 0.0022^{f g}$ & $0.037 \pm 0.0003^{d e}$ \\
\hline $10 \mu \mathrm{M} \mathrm{Brz}$ & $0.021 \pm 0.0011^{g}$ & $0.114 \pm 0.0018^{i}$ & $0.011 \pm 0.0003^{g h}$ \\
\hline $0.001 \mu \mathrm{M}$ EBL & $0.037 \pm 0.002^{e}$ & $0.186 \pm 0.0055^{f g}$ & $0.037 \pm 0.0007^{d e}$ \\
\hline $0.01 \mu \mathrm{M}$ EBL & $0.038 \pm 0.0016^{e}$ & $0.186 \pm 0.0045^{f g}$ & $0.036 \pm 0.0003^{d e}$ \\
\hline $0.1 \mu \mathrm{M}$ EBL & $0.059 \pm 0.0019^{b}$ & $0.201 \pm 0.0011^{d e}$ & $0.048 \pm 0.0005^{c}$ \\
\hline $1 \mu \mathrm{M}$ EBL & $0.015 \pm 0.0003^{h}$ & $0.150 \pm 0.0036^{h}$ & $0.014 \pm 0.0007^{g}$ \\
\hline
\end{tabular}


Table 2 (continued)

\begin{tabular}{llll}
\hline Treatment & \multicolumn{2}{l}{ Brassinosteroid $\left(\mathrm{ng} \mathrm{g}^{-1}\right.$ fresh weight $)$} & \\
\cline { 2 - 4 } & TY & $6 \mathrm{dTY}$ & $6 \mathrm{dCS}$ \\
\hline $10 \mu \mathrm{M} \mathrm{EBL}$ & $0.009 \pm 0.0005^{i}$ & $0.110 \pm 0.0022^{i}$ & $0.009 \pm 0.0002^{h}$ \\
$0.1 \mu \mathrm{M} \mathrm{EBL}+0.1 \mu \mathrm{M} \mathrm{Brz}$ & $0.036 \pm 0.002^{e}$ & $0.178 \pm 0.0044^{g}$ & $0.031 \pm 0.001^{f}$ \\
$0.1 \mu \mathrm{M} \mathrm{EBL}+1 \mu \mathrm{M} \mathrm{Brz}$ & $0.078 \pm 0.0008^{a}$ & $0.389 \pm 0.0055^{a}$ & $0.061 \pm 0.0006^{a}$ \\
$0.1 \mu \mathrm{M} \mathrm{EBL}+10 \mu \mathrm{M} \mathrm{Brz}$ & $0.051 \pm 0.0028^{c}$ & $0.264 \pm 0.0052^{c}$ & $0.052 \pm 0.0022^{b}$ \\
$1 \mu \mathrm{M} \mathrm{Brz}+0.001 \mu \mathrm{M} \mathrm{EBL}$ & $0.045 \pm 0.0014^{d}$ & $0.210 \pm 0.0083^{d}$ & $0.048 \pm 0.0022^{c}$ \\
$1 \mu \mathrm{M} \mathrm{Brz}+0.01 \mu \mathrm{M} \mathrm{EBL}$ & $0.052 \pm 0.0011^{c}$ & $0.292 \pm 0.0051^{b}$ & $0.052 \pm 0.0023^{b}$ \\
$1 \mu \mathrm{M} \mathrm{Brz}+0.1 \mu \mathrm{M} \mathrm{EBL}$ & $0.078 \pm 0.0008^{a}$ & $0.389 \pm 0.0055^{a}$ & $0.061 \pm 0.0006^{a}$ \\
$1 \mu \mathrm{M} \mathrm{Brz}+1 \mu \mathrm{M} \mathrm{EBL}$ & $0.027 \pm 0.0011^{f}$ & $0.202 \pm 0.0067^{d}$ & $0.039 \pm 0.0021^{d}$ \\
$1 \mu \mathrm{M} \mathrm{Brz}+10 \mu \mathrm{M} \mathrm{EBL}$ & $0.022 \pm 0.0004^{g}$ & $0.192 \pm 0.0012^{e f}$ & $0.035 \pm 0.0019^{e}$ \\
\hline
\end{tabular}

Data represent the mean $(n=8) \pm$ standard deviation (SD). Means \pm SD connected by the same letter are not significantly different $(p \geq 0.05)$ according to Tukey's post hoc test; data were grouped according to treatments of each compound)

BR biosynthesis inhibitor-Brz. Barley growth (Fig. 1) and the composition of BRs were modified in leaves treated with Brz (Table 1). However, the inhibition could be reversed by the exogenous treatment with EBL. Similarly, it was also reported that Brz induced dwarfism and curly phenotypes in soybean (Glycine max) (Mazorra et al. 2004), dark-green leaves in light-grown cress (Lepidium sativum), cucumber (Cucumis sativus), tobacco (Nicotiana tabacum) (Nagata et al. 2001; Sekimata et al. 2001) and inhibition of Wolffia arrhiza growth (Bajguz and Asami 2005).

In cereals, the content and the profile of BRs were influenced by the exogenous application of BRs (Janeczko and Swaczynova 2010). The impact of BR treatment on fluctuations of endogenous BR content may be explained by alterations of intermediate steps of BR metabolism or the direct influence on the biosynthetic pathways (Joo et al. 2015).

Both pre-sowing soaking of the seeds or spraying the plants in the heading phase with an aqueous solution containing traces of ethanol increased the content of BL as well as ECS relative to the content of these compounds in the untreated seeds (Janeczko et al. 2010). Similarly to these results, EBL treatment $(0.001-0.1 \mu \mathrm{M})$ also increased the endogenous content of BRs in seedlings of cv. Golden Promise but decreased BRs level when applied in higher concentrations, i.e. $1-10 \mu \mathrm{M}$. The treatment of seeds or plants also affected the BRs' profile in the newly emerging grains. BRs are most often applied as a spray on the aerial parts of plants (Kroutil et al. 2010), while application through the root system (Janeczko and Swaczynova 2010) or through pre-sowing soaking of the seeds are less often reported (Sairam 1994).

It has been found that the uptake and transport of the exogenous BRs depend on the application method (Symons et al. 2008). More efficient BR uptake and subsequently BR transport were associated with root application because roots' function is to uptake substances from the soil solution. The application of EBL to roots led to twofold increase of the endogenous content of EBL in the leaves compared to the control. Furthermore, the amount of EBL increased threefold after the application of a 20-fold higher concentration in leaves (Janeczko and Swaczynova 2010). Presented results indicate that application of EBL to hydroponically cultured seedlings of barley has affected the content of BRs in leaves and roots in a dose-dependent manner. Effective BR transport applies only to hydroponic cultures, where direct and permanent contact of the solution with the root is ensured. Therefore, this study confirms that the exogenous BR could effectively either stimulate or inhibit the biosynthesis of BRs.

Present results revealed that the exogenous application of EBL at high concentrations $(1-10 \mu \mathrm{M})$ inhibits the elongation of barley seedlings and root growth. Similarly, the bean second internode bioassay shows that application of high BR concentration resulted in the inhibition of growth (Thompson et al. 1981; Swaczynová et al. 2006). On the other hand, low concentration of BR exerts a growth-promoting effect in stems of seedlings and young plants (Horvath et al. 2003). The effect of BRs on root growth depends on the applied BR concentration, i.e. low concentrations can stimulate primary root growth, while higher ones can inhibit it (Roddick 1994; Haubrick and Assmann 2006). EBL has an inhibitory effect on root formation in mung bean (Vigna radiata), wheat, maize, tomato (Lycopersicon esculentum) and Arabidopsis seedlings (Guan and Roddick 1988a, b; Roddick and Ikekawa 1992; Clouse et al. 1993; Roddick et al. 1993).

Auxin and BRs are known for their interdependence and demonstration of synergistic interactions in promoting mesocotyl elongation in maize seedlings (Kutschera and Wang 2016). Despite the fact that the cross regulation between these phytohormones has been observed at several levels, including auxin activation of BR biosynthetic genes, BR regulation of the expression levels of auxin transporters and BIN2 phosphorylation of ARF2, 


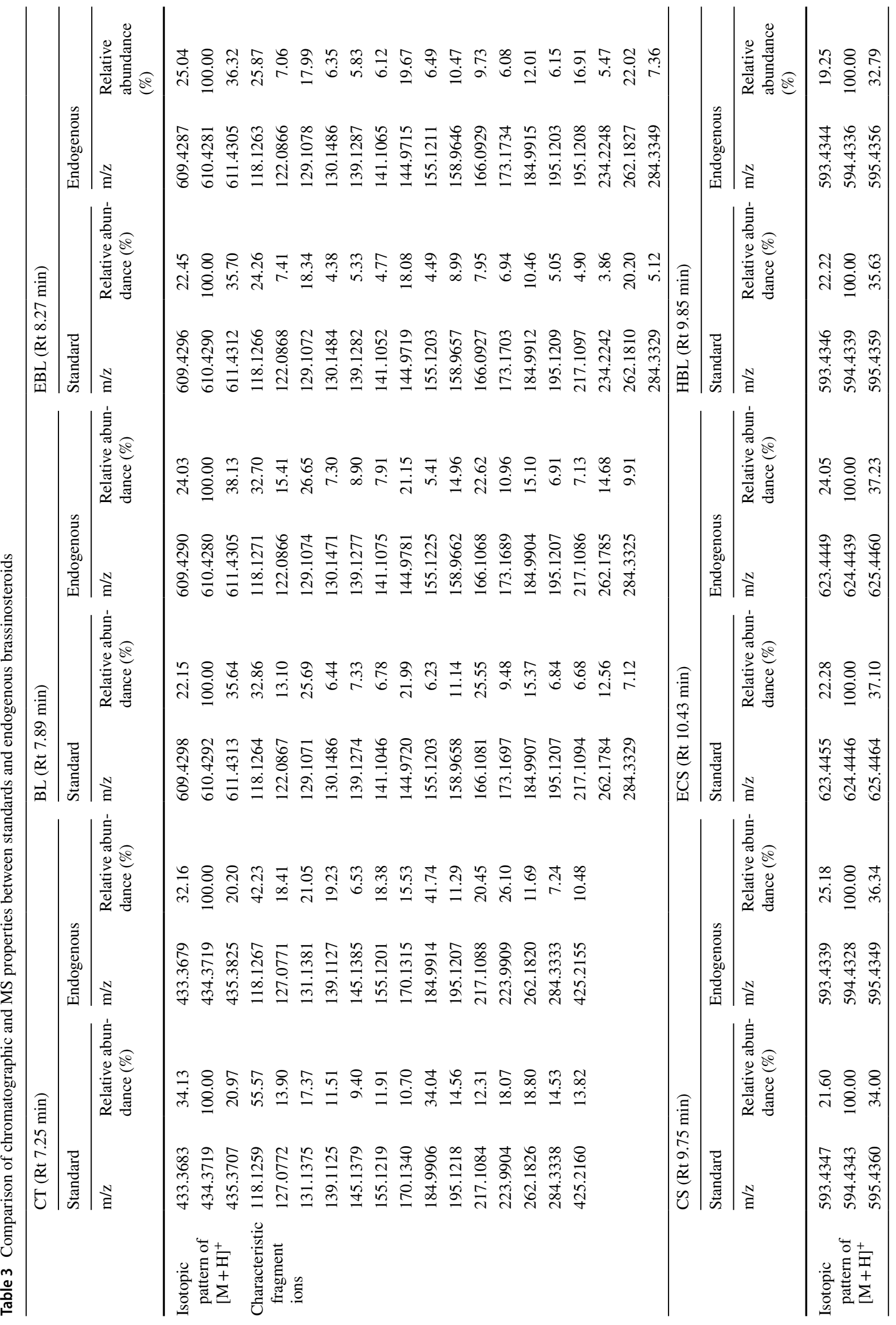




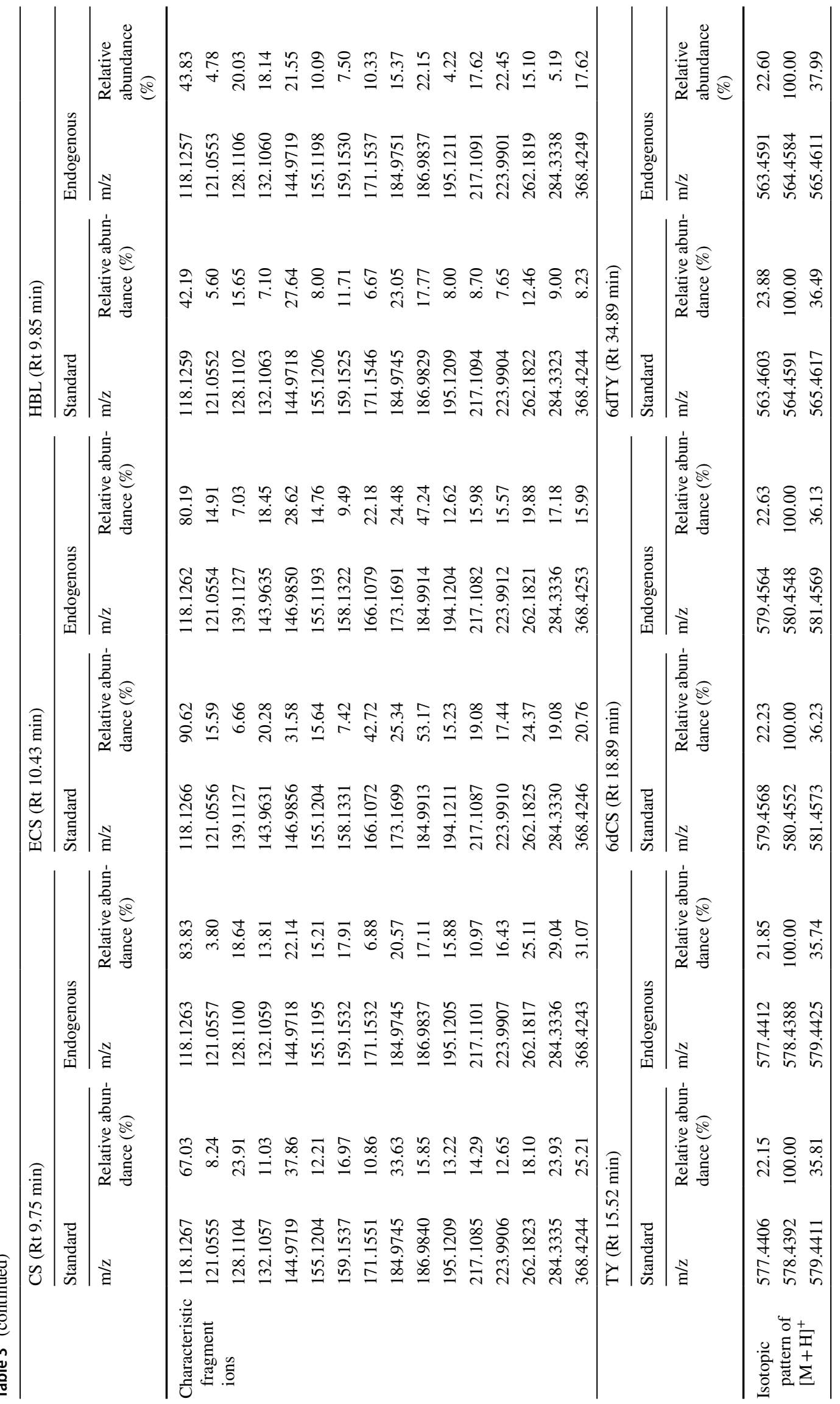




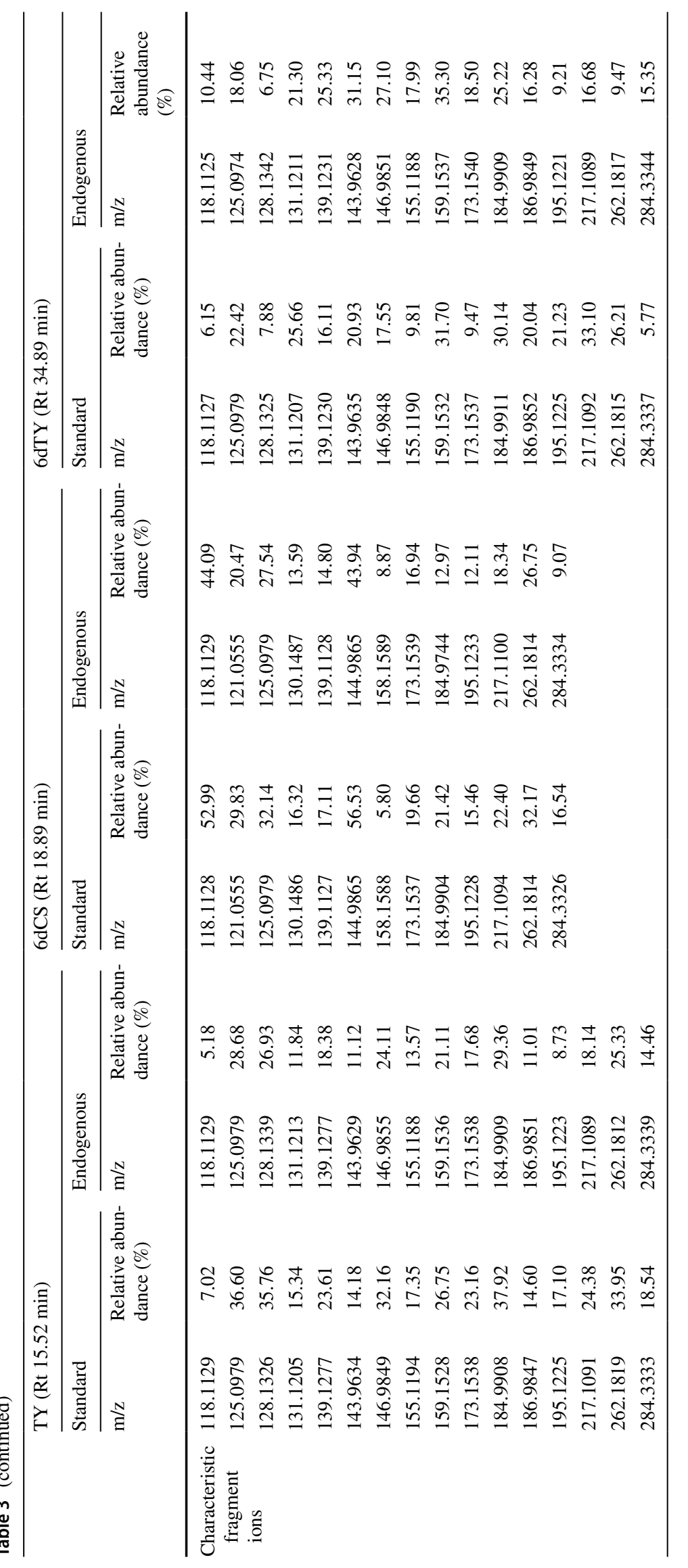




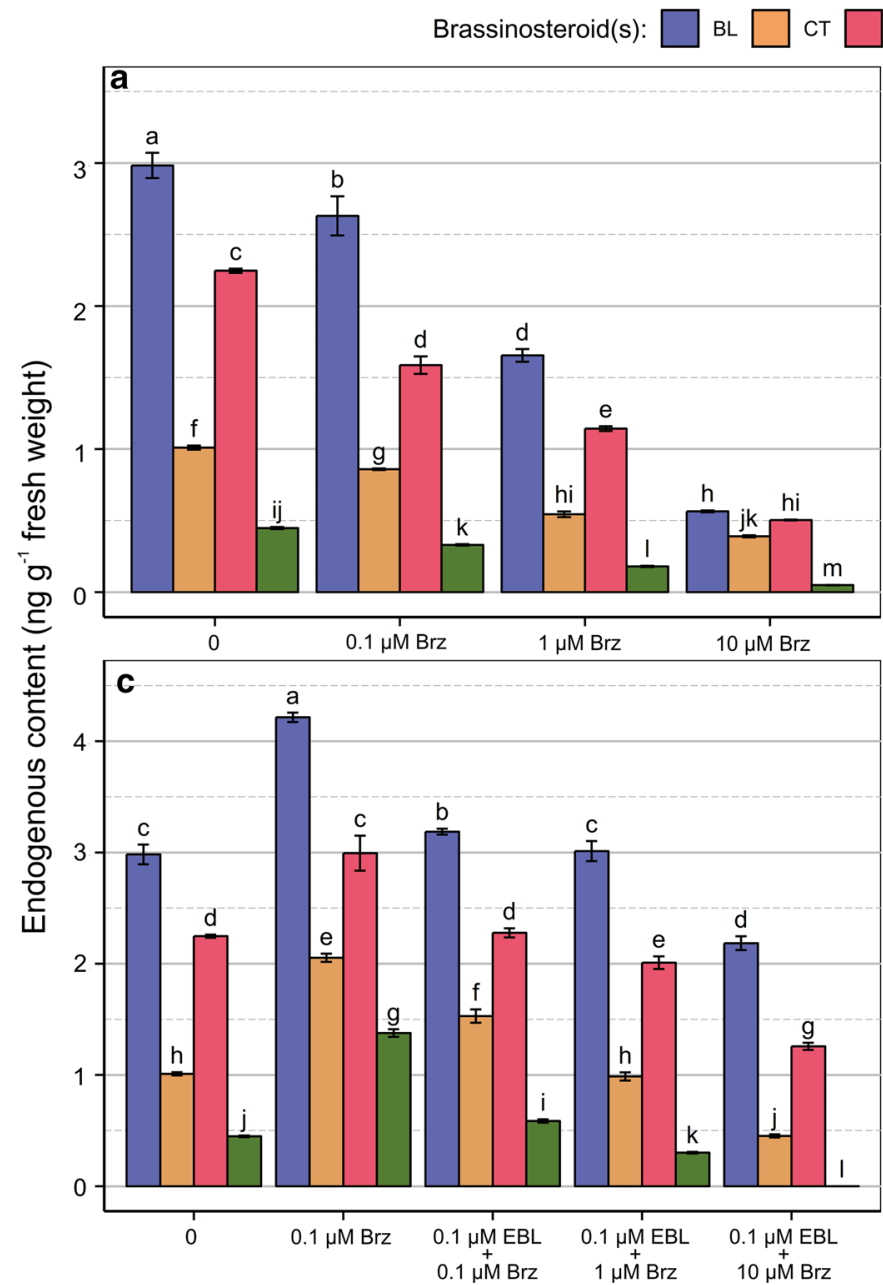

Fig. 2 Endogenous content of brassinosteroids in barley leaves treated with: (a) brassinazole (Brz), (b) 24-epibrassinolide (EBL), (c and d) Brz and/or EBL vs. control. Bars show the mean with the

its mechanisms appear unclear and insufficient to explain their mutual interdependence (Oh et al. 2014). It is also known that BR not only does regulate cell elongation by modulating gibberellin (GA) metabolism in rice, but also promotes the accumulation of GA by regulating the expression of its metabolic genes to stimulate cell elongation. Low BR concentrations induce GA biosynthesis and inhibit GA inactivation, causing increased GA levels and cell elongation; however, high concentrations induce GA inactivation and the inhibition of cell elongation. In contrast, low GA concentrations repress BR signalling as well as biosynthesise BR through a feedback mechanism. Furthermore, high GA concentrations can activate BR
$C S \square E C S+E B L+H B L+T Y+6 d T Y+6 d C S$
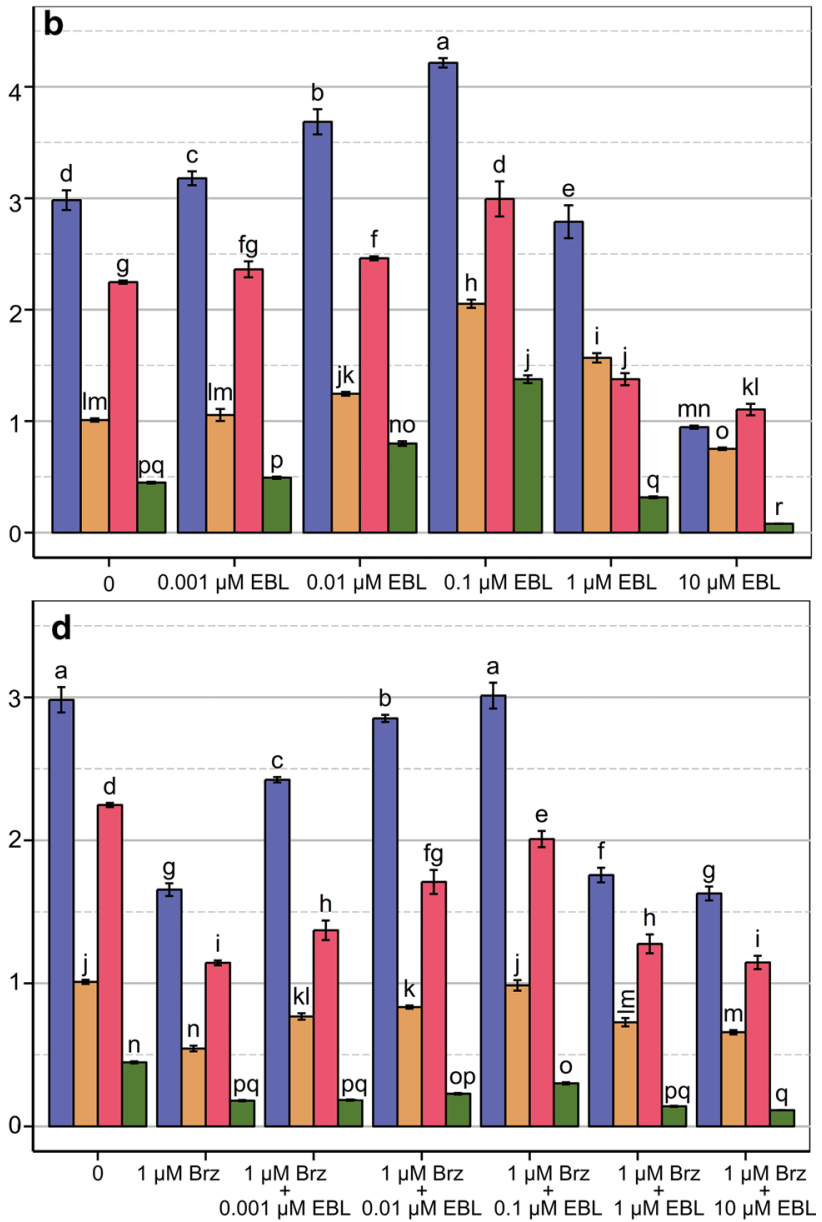

respective standard deviation. Means $(n=8)$ with at least one letter the same are not significantly different $(p \geq 0.05)$ according to Tukey's post hoc test (data were grouped according to concentration)

signalling pathway to facilitate cell elongation (Tong et al. 2014). Further research is required to explain the effect of interaction between BRs and other phytohormones on the level of these compounds in barley seedlings.

Author contribution statement $\mathrm{AB}$ and $\mathrm{WO}$ conceived the study and wrote the manuscript. $\mathrm{AB}$ and $\mathrm{AG}$ performed the barley cultivation. $\mathrm{AB}$ assembled photographic documentation and performed statistical analysis. $\mathrm{AB}, \mathrm{MC}$, and $\mathrm{AG}$ performed the brassinosteroid extraction. AP-N performed the interpretation of LC-MS data. All authors read and approved the final manuscript.

Acknowledgements This project has been financed from the funds of the National Science Centre allocated on the basis of the decision number DEC-2014/13/B/NZ9/02381. This work was funded by the Ministry 


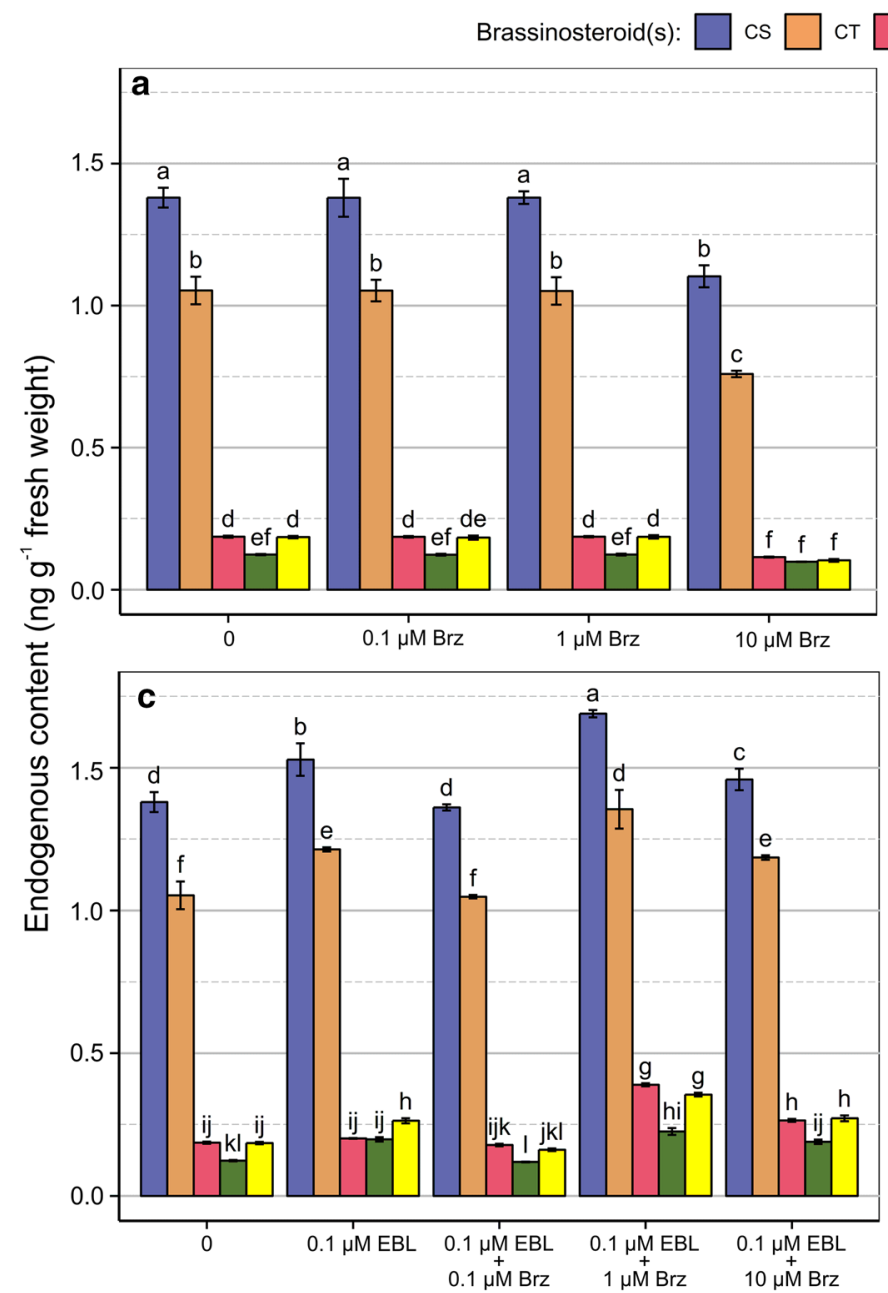

$\square$ 6dTY $\square$ HBL $\square E C S+B L+E B L+T Y+6 d C S$
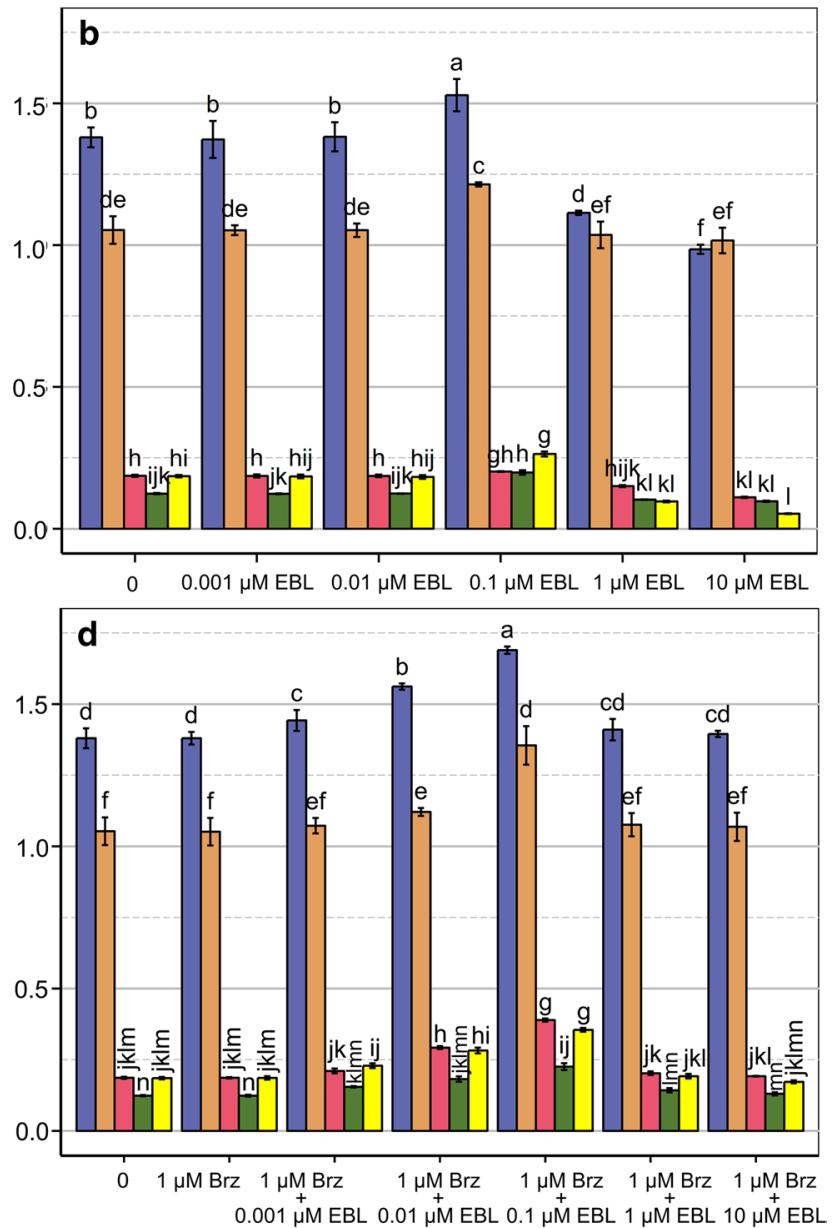

Fig. 3 Endogenous content of brassinosteroids in barley roots treated with: (a) brassinazole (Brz), (b) 24-epibrassinolide (EBL), (c and d) Brz and/or EBL vs. control. Bars show the mean with the respective

of Science and Higher Education as part of subsidies for maintaining research potential awarded to the Faculty of Biology and Chemistry of the University of Bialystok. The equipment of Center BioNanoTecho University of Bialystok (Q-TOF LC/MS) was partly supported by EU funds via Project number POPW.01.03.00-20-004/11.

\section{Compliance with ethical standards}

Conflict of interest The authors declare that the research was conducted in the absence of any commercial relationships, and there was no potential conflict of interest.

OpenAccess This article is distributed under the terms of the Creative Commons Attribution 4.0 International License (http://creativeco mmons.org/licenses/by/4.0/), which permits unrestricted use, distribution, and reproduction in any medium, provided you give appropriate credit to the original author(s) and the source, provide a link to the Creative Commons license, and indicate if changes were made. standard deviation. Means $(n=8)$ with at least one letter the same are not significantly different $(p \geq 0.05)$ according to Tukey's post hoc test (data were grouped according to concentration)

\section{References}

Abe H, Nakamura K, Morishita T, Uchiyama M, Takatsuto S, Ikekawa N (1984) Endogenous brassinosteroids of the rice plant-castasterone and dolichosterone. Agr Biol Chem 48:1103-1104. https ://doi.org/10.1080/00021369.1984.10866278

Abe H, Takatsuto S, Nakayama M, Yokota T (1995) 28-Homotyphasterol, a new natural brassinosteroid from rice (Oryza sativa L.) bran. Biosci Biotech Bioch 59:176-178. https://doi.org/10.1271/ Bbb.59.176

Antonchick AP, Schneider B, Zhabinskii VN, Konstantinova OV, Khripach VA (2003) Biosynthesis of 2,3-epoxybrassinosteroids in seedlings of Secale cereale. Phytochemistry 63:771-776

Antonchick A, Svatos A, Schneider B, Konstantinova OV, Zhabinskii VN, Khripach VA (2005) 2,3-Epoxybrassinosteroids are intermediates in the biosynthesis of castasterone in seedlings of Secale cereale. Phytochemistry 66:65-72

Asahina M, Tamaki Y, Sakamoto T, Shibata K, Nomura T, Yokota T (2014) Blue light-promoted rice leaf bending and unrolling are due to up-regulated brassinosteroid biosynthesis genes accompanied by accumulation of castasterone. Phytochemistry 104:21-29. https://doi.org/10.1016/j.phytochem.2014.04.017 
Asami T, Yoshida S (1999) Brassinosteroid biosynthesis inhibitors. Trends Plant Sci 4:348-353. https://doi.org/10.1016/S1360 -1385(99)01456-9

Asami T, Min YK, Nagata N, Yamagishi K, Takatsuto S, Fujioka S, Murofushi N, Yamaguchi I, Yoshida S (2000) Characterization of brassinazole, a triazole-type brassinosteroid biosynthesis inhibitor. Plant Physiol 123:93-99. https://doi.org/10.1104/Pp.123.1.93

Asami T, Mizutani M, Shimada Y, Goda H, Kitahata N, Sekimata K, Han SY, Fujioka S, Takatsuto S, Sakata K, Yoshida S (2003) Triadimefon, a fungicidal triazole-type $\mathrm{P} 450$ inhibitor, induces brassinosteroid deficiency-like phenotypes in plants and binds to DWF4 protein in the brassinosteroid biosynthesis pathway. Biochem J 369:71-76. https://doi.org/10.1042/Bj20020835

Bajguz A, Tretyn A (2003) The chemical characteristic and distribution of brassinosteroids in plants. Phytochemistry 62:1027-1046. https ://doi.org/10.1016/S0031-9422(02)00656-8

Bajguz A, Asami T (2005) Suppression of Wolffia arrhiza growth by brassinazole, an inhibitor of brassinosteroid biosynthesis and its restoration by endogenous 24-epibrassinolide. Phytochemistry 66:1787-1796. https://doi.org/10.1016/j.phytochem.2005.06.005

Kanwar MK, Bajguz A, Zhou J, Bhardwaj R (2017) Analysis of brassinosteroids in plants. J Plant Growth Regul 36:1002-1030. https:// doi.org/10.1007/s00344-017-9732-4

Bajguz A (2007) Metabolism of brassinosteroids in plants. Plant Physiol Bioch 45:95-107. https://doi.org/10.1016/j.plaphy.2007.01.002

Caban M, Migowska N, Stepnowski P, Kwiatkowski M, Kumirska J (2012) Matrix effects and recovery calculations in analyses of pharmaceuticals based on the determination of $\beta$-blockers and $\beta$-agonists in environmental samples. J Chromatogr A 1258:117127. https://doi.org/10.1016/j.chroma.2012.08.029

Bajguz A, Piotrowska-Niczyporuk A (2014) Brassinosteroids implicated in growth and stress responses. In: Tran L-SP, Pal S (eds) Phytohormones: a window to metabolism, signaling and biotechnological applications. Springer, New York, pp 163-190. https:// doi.org/10.1007/978-1-4939-0491-4_6

Chung Y, Choe S (2013) The regulation of brassinosteroid biosynthesis in Arabidopsis. Crit Rev Plant Sci 32:396-410. https://doi. org/10.1080/07352689.2013.797856

Clouse SD, Hall AF, Langford M, Mcmorris TC, Baker ME (1993) Physiological and molecular effects of brassinosteroids on Arabidopsis thaliana. J Plant Growth Regul 12:61-66

da Silva LJ (2010) Laercio-package: Duncan test, Tukey test and Scott-Knott test. https://CRAN.R-project.org/package=laercio. Accessed 20 Feb 2015

Dockter C, Gruszka D, Braumann I, Druka A, Druka I, Franckowiak J, Gough SP, Janeczko A, Kurowska M, Lundqvist J, Lundqvist U, Marzec M, Matyszczak I, Muller AH, Oklestkova J, Schulz B, Zakhrabekova S, Hansson M (2014) Induced variations in brassinosteroid genes define barley height and sturdiness, and expand the green revolution genetic toolkit. Plant Physiol 166:1912-1927. https://doi.org/10.1104/pp.114.250738

Fox J, Weisberg S (2011) An R Companion to applied regression, 2nd edn. SAGE Publications Inc, Thousand Oaks

Gamoh K, Okamoto N, Takatsuto S, Tejima I (1990) Determination of traces of natural brassinosteroids as dansylaminophenylboronates by liquid chromatography with fluorimetric detection. Anal Chim Acta 228:101-105

Gruszka D, Gorniak M, Glodowska E, Wierus E, Oklestkova J, Janeczko A, Maluszynski M, Szarejko I (2016a) A reverse-genetics mutational analysis of the barley $H v D W A R F$ gene results in identification of a series of alleles and mutants with short stature of various degree and disturbance in BR biosynthesis allowing a new insight into the process. Int J Mol Sci 17:600. https://doi. org/10.3390/ijms17040600

Gruszka D, Janeczko A, Dziurka M, Pociecha E, Oklestkova J, Szarejko I (2016b) Barley brassinosteroid mutants provide an insight into phytohormonal homeostasis in plant reaction to drought stress. Front Plant Sci 7:1824. https://doi.org/10.3389/fpls.2016.01824

Guan M, Roddick JG (1988a) Comparison of the effects of epibrassinolide and steroidal estrogens on adventitious root growth and early shoot development in mung bean cuttings. Physiol Plantarum 73:426-431. https://doi.org/10.1111/j.1399-3054.1988. tb00621.x

Guan M, Roddick JG (1988b) Epibrassinolide-inhibition of development of excised, adventitious and intact roots of tomato (Lycopersicon esculentum): comparison with the effects of steroidal estrogens. Physiol Plantarum 74:720-726. https://doi. org/10.1111/j.1399-3054.1988.tb02043.x

Haubrick LL, Assmann SM (2006) Brassinosteroids and plant function: some clues, more puzzles. Plant Cell Environ 29:446-457

Horvath DP, Schaffer R, West M, Wisman E (2003) Arabidopsis microarrays identify conserved and differentially expressed genes involved in shoot growth and development from distantly related plant species. Plant J 34:125-134. https://doi. org/10.1046/j.1365-313X.2003.01706.x

Janeczko A, Swaczynova J (2010) Endogenous brassinosteroids in wheat treated with 24-epibrassinolide. Biol Plantarum 54:477482. https://doi.org/10.1007/s10535-010-0084-1

Janeczko A, Biesaga-Koscielniak J, Oklest'kova J, Filek M, Dziurka M, Szarek-Lukaszewska G, Koscielniak J (2010) Role of 24-epibrassinolide in wheat production: physiological effects and uptake. J Agron Crop Sci 196:311-321. https://doi. org/10.1111/j.1439-037X.2009.00413.x

Janeczko A, Oklestkova J, Pociecha E, Koscielniak J, Mirek M (2011) Physiological effects and transport of 24-epibrassinolide in heat-stressed barley. Acta Physiol Plant 33:1249-1259. https ://doi.org/10.1007/s11738-010-0655-y

Joo S-H, Jang M-S, Kim MK, Lee J-E, Kim S-K (2015) Biosynthetic relationship between $\mathrm{C}_{28}$-brassinosteroids and $\mathrm{C}_{29}$-brassinosteroids in rice (Oryza sativa) seedlings. Phytochemistry 111:84-90

Kim YS, Kim TW, Kim SK (2005) Brassinosteroids are inherently biosynthesized in the primary roots of maize, Zea mays L. Phytochemistry 66:1000-1006

Kroutil M, Hejtmánková A, Lachman J (2010) Effect of spring wheat (Triticum aestivum L.) treatment with brassinosteroids on the content of cadmium and lead in plant aerial biomass and grain. Plant Soil Environ 56:43-50. https://doi.org/10.17221 /148/2009-PSE

Kutschera U, Wang ZY (2012) Brassinosteroid action in flowering plants: a Darwinian perspective. J Exp Bot 63:3511-3522. https ://doi.org/10.1093/jxb/ers065

Kutschera U, Wang ZY (2016) Growth-limiting proteins in maize coleoptiles and the auxin-brassinosteroid hypothesis of mesocotyl elongation. Protoplasma 253:3-14. https://doi. org/10.1007/s00709-015-0787-4

Mazorra LM, Nunez M, Napoles MC, Yoshida S, Robaina C, Coll F, Asami T (2004) Effects of structural analogs of brassinosteroids on the recovery of growth inhibition by a specific brassinosteroid biosynthesis inhibitor. Plant Growth Regul 44:183-185. https://doi.org/10.1023/B:Grow.0000049412.30708.D3

Nagata N, Asami T, Yoshida S (2001) Brassinazole, an inhibitor of brassinosteroid biosynthesis, inhibits development of secondary xylem in cress plants (Lepidium sativum). Plant Cell Physiol 42:1006-1011. https://doi.org/10.1093/Pcp/Pce122

Oh E, Zhu JY, Bai MY, Arenhart RA, Sun Y, Wang ZY (2014) Cell elongation is regulated through a central circuit of interacting transcription factors in the Arabidopsis hypocotyl. Elife 3:e03031. https://doi.org/10.7554/elife.03031

Park KH, Park JD, Hyun KH, Nakayama M, Yokota T (1994) Brassinosteroids and monoglycerides with brassinosteroid-like activity in immature seeds of Oryza sativa and Perilla frutescens and 
in cultured cells of Nicotiana tabacum. Biosci Biotech Bioch 58:2241-2243. https://doi.org/10.1271/Bbb.58.2241

R Core Team (2018) R: a language and environment for statistical computing (R version 3.5.2, Eggshell Igloo). R Foundation for Statistical Computing, Vienna, Austria. https://www.R-proje ct.org/. Accessed 20 Dec 2018

Roddick JG (1994) Comparative root-growth inhibitory activity of 4 brassinosteroids. Phytochemistry 37:1277-1281

Roddick JG, Ikekawa N (1992) Modification of root and shoot development in monocotyledon and dicotyledon seedlings by 24-epibrassinolide. J Plant Physiol 140:70-74

Roddick JG, Rijnenberg AL, Ikekawa N (1993) Developmental effects of 24-epibrassinolide in excised roots of tomato grown in vitro. Physiol Plantarum 87:453-458

Sairam RK (1994) Effects of homobrassinolide application on plant metabolism and grain yield under irrigated and moisture-stress conditions of 2 wheat-varieties. Plant Growth Regul 14:173-181

Schmidt J, Spengler B, Yokota T, Nakayama M, Takatsuto S, Voigt B, Adam G (1995) Secasterone, the first naturally occurring 2,3-epoxybrassinosteroid from Secale cereale. Phytochemistry 38:1095-1097. https://doi.org/10.1016/0031-9422(94)00797-W

Sekimata K, Kimura T, Kaneko I, Nakano T, Yoneyama K, Takeuchi Y, Yoshida S, Asami T (2001) A specific brassinosteroid biosynthesis inhibitor, Brz 2001: evaluation of its effects on Arabidopsis, cress, tobacco, and rice. Planta 213:716-721. https://doi. org/10.1007/s004250100546

Shimada K, Abe H, Takatsuto S, Nakayama M, Yokota T (1996) Identification of castasterone and teasterone from seeds of canary grass (Phalaris canariensis). Rec Res Dev Chem Pharm Sci 1:1-5

Suzuki Y, Yamaguchi I, Yokota T, Takahashi N (1986) Identification of castasterone, typhasterol and teasterone from the pollen of Zea mays. Agr Biol Chem 50:3133-3138. https://doi. org/10.1080/00021369.1986.10867873

Suzuki H, Fujioka S, Takatsuto S, Yokota T, Murofushi N, Sakurai A (1995) Biosynthesis of brassinosteroids in seedlings of Catharanthus roseus, Nicotiana tabacum, and Oryza sativa. Biosci Biotech Bioch 59:168-172

Swaczynová J, Sisa M, Hnilickova J, Kohout L, Strnad M (2006) Synthesis, biological, immunological and anticancer properties of a new brassinosteroid ligand. Pol J Chem 80:629-636

Symons GM, Ross JJ, Jager CE, Reid JB (2008) Brassinosteroid transport. J Exp Bot 59:17-24. https://doi.org/10.1093/jxb/erm098

Tarkowska D, Strnad M (2018) Isoprenoid-derived plant signaling molecules: biosynthesis and biological importance. Planta 247:10511066. https://doi.org/10.1007/s00425-018-2878-x
Taylor PE, Spuck K, Smith PM, Sasse JM, Yokota T, Griffiths PG, Cameron DW (1993) Detection of brassinosteroids in pollen of Lolium perenne L. by immunocytochemistry. Planta 189:91-100

Thompson MJ, Mandava NB, Meudt WJ, Lusby WR, Spaulding DW (1981) Synthesis and biological activity of brassinolide and its $22 \beta, 23 \beta$-isomer: novel plant growth-promoting steroids. Steroids 38:567-580. https://doi.org/10.1016/0039-128X(81)90055-6

Tong HN, Xiao YH, Liu DP, Gao SP, Liu LC, Yin YH, Jin Y, Qian Q, Chu CC (2014) Brassinosteroid regulates cell elongation by modulating gibberellin metabolism in rice. Plant Cell 26:4376-4393. https://doi.org/10.1105/tpc.114.132092

Wu CY, Trieu A, Radhakrishnan P, Kwok SF, Harris S, Zhang K, Wang JL, Wan JM, Zhai HQ, Takatsuto S, Matsumoto S, Fujioka S, Feldmann KA, Pennell RI (2008) Brassinosteroids regulate grain filling in rice. Plant Cell 20:2130-2145. https://doi.org/10.1105/ tpc.107.055087

Xin PY, Yan JJ, Fan JS, Chu JF, Yan CY (2013) An improved simplified high-sensitivity quantification method for determining brassinosteroids in different tissues of rice and Arabidopsis. Plant Physiol 162:2056-2066

Ye HX, Li L, Yin YH (2011) Recent advances in the regulation of brassinosteroid signaling and biosynthesis pathways. J Integr Plant Biol 53:455-468. https://doi.org/10.1111/j.1744-7909.2011.01046 .x

Yokota T, Nakayama M, Wakisaka T, Schmidt J, Adam G (1994) 3-Dehydroteasterone, a 3,6-diketobrassinosteroid as a possible biosynthetic intermediate of brassinolide form wheat grain. Biosci Biotech Bioch 58:1183-1185. https://doi.org/10.1271/ Bbb.58.1183

Zhabinskii VN, Khripach NB, Khripach VA (2015) Steroid plant hormones: effects outside plant kingdom. Steroids 97:87-97. https:// doi.org/10.1016/j.steroids.2014.08.025

Zhao BL, Li J (2012) Regulation of brassinosteroid biosynthesis and inactivation. J Integr Plant Biol 54:746-759. https://doi.org/10.1 111/j.1744-7909.2012.01168.x

Zullo MAT (2018) Brassinosteroids and related compounds. Lambert Academic Publishing, Beau Bassin

Publisher's Note Springer Nature remains neutral with regard to jurisdictional claims in published maps and institutional affiliations. 